\title{
PENDISTRIBUSIAN KARTU INDONESIA PINTAR (KIP)
}

\author{
Ratna Indah Cahyaningsih \\ Fakultas Keguruan dan IImu Pendidikan Universitas Kristen Satya Wacana \\ 292015093@student.uksw.edu
}

\begin{abstract}
Smart Indonesia Program (PIP) is an enhanced government support program for Poor Students (BSM). This PIP program is expected to help economically disadvantaged students and can ease the burden of disadvantaged families, as well as to recall dropped students due to delinquent fees. It is hoped that there will be no more reason for not continuing education to a higher level because of cost issues. For Use of funds to be used as effectively and efficiently as possible. Thus the PIP program can support a 12-year compulsory government program. Both of these programs can go hand in hand with the national goal of the Indonesian nation that is Introduce the Life of the Nation.
\end{abstract}

Keywords: Distribution of Smart Indonesian Card, Smart Indonesian Card, student.

\begin{abstract}
ABSTRAK
Program Indonesia Pintar (PIP) adalah program pendukung pemerintah Bantuan Siswa Miskin (BSM) yang disempurnakan. Program PIP ini diharapkan dapat membantu siswa yang kurang mampu dari segi ekonomi dan dapat meringankan beban keluarga yang kurang mampu, serta menarik kembali siswa yang putus sekolah dikarenakan tunggakan biaya. Maka diharapkan tidak ada lagi alasan untuk tidak melanjutkan pendidikan ke jenjang yang lebih tinggi lagi karena masalah biaya. Untuk Penggunaan dana agar dapat digunakan seefektif dan efisien mungkin. Dengan demikian program PIP dapat mendukung program pemerintah wajib belajar 12 tahun. Kedua program tersebut dapat beriringan menjalankan tujuan nasional bangsa Indonesia yaitu Mencerdaskan Kehidupan Bangsa.
\end{abstract}

Kata kunci : Pendistribusian Kartu Indonesia Pintar, Kartu Indonesia Pintar, siswa. 


\section{A. Pendahuluan}

Program Indonesia Pintar (PIP) yaitu suatu program yang menjadi prioritas oleh Presiden Republik Indonesia Ir. Joko Widodo yang dirancang khusus untuk membantu anak yang berasal dari keluarga miskin dan kurang mampu. Agar pendidikannya dapat dijamin dari Sekolah Dasar (SD), Sekolah Menengah Pertama (SMP), dan Sekolah Menengah Atas (SMA) atau Sekolah Menengah Kejuruan (SMK) sederajat.

Untuk program Indonesia Pintar ini, Presiden Joko Widodo bekerja sama dengan Kementrian Agama (kemenag), Kementrian Pendidikan dan Kebudayaan (Kemendikbud) dan juga Kementrian Sosial (kemensos). Hal ini dilakukan untuk untuk membantu dan mempermudah jalannya program Indonesia Pintar. Selain itu, Program Indonesia Pintar ini, digunakan membantu masyarakat yang kurang mampu untuk membiyayai anak mereka, menekan atau mencegah siswa putus sekolah dan dapat membantu siswa yang putus sekolah untuk melanjutkan satuan pendidikan formal maupun informal, yang sebagian berasal dari keluarga penerima kartu Program Keluarga Harapan (PKH) dan kartu Perlindungan Sosial (KPS).

Dalam penerapan program Indonesia Pintar, Indonesia sehat dan Indonesia sejahtera memiliki payung hukum yang dapat dipertanggung jawabkan, pelaksanaannya mulai dari pasal 34 ayat (1) dan (3) UUD 1945, UU Nomor 25/2004 tentang sistem perencanaan pembangunan nasional yang menyebutkan bahwa janji - janji presiden saat kampanye pemilihan presiden wajib dilaksanaakan sesuai dengan ketentuan peraturan perundang - undangan yang berlaku, mengatur kewajiban negara memberikan sistem jaminan sosial bagi seluruh rakyat serta Instruksi presiden Nomor 7 Tahun 2014 tentang pelaksanaan Program Simpanan Keluarga Sejahtera, Program Indonesia Sehat untuk membangun Keluarga Produktif, mengamanatkan agar Kartu Indonesia Pintar diberikan 
kepada anak - anak yang berusia 6 sampai 21 tahun dari keluarga pemegang Kartu Keluarga Sejahtera (KKS) sebagai identitas untuk mendapatkan manfaat Program Indonesia pintar.

Kartu Indonesia Pintar (KIP) harus tepat sasaran agar dapat digunakan dengan sebaik mungkin, di daerah diharapkan agar pemerintahan yang menangani pembagian KIP ini, di seleksi sebaik mungkin untuk menghindari salah sasaran. Karna di setiap daerah di Indonesia banyak masyarakat yang sangat membutuhkan bantuan dari pemerintah, mereka yang sangat membutuhkan dana dan biaya untuk membantu meringankan perekonomian keluarga.

Masyarakat

Indonesia

diharapkan agar menggunakan Kartu Indonesia Pintar dengan sebaik mungkin, guna membantu program pemerintah yaitu menekan angka putus sekolah yang dilatar belakangi oleh biaya. Jadi, masyarakat harus sejalan dengan program pemerintah ini. Sebagai orang tua agar lebih bijak dalam membelikan perlengkapan sekolah anak, dengan demikian biaya yang dikeluarkan dapat seefektif mungkin, membeli seperlunya saja.

Program Indonesia Pintar (PIP) melalui Kartu Indonesia Pintar (KIP) adalah salah satu program nasional (tercantum dalam Rencana Pembangunan Jangka Menengah Nasional 2015 sampai 2019) yang bertujuan untuk :

1. Meningkatkan angka partisipasi pendidikan dasar dan menengah

2. Meningkatkan angka keberlanjutan pendidikan yang ditandai dengan menurunnya angka putus sekolah dan angka melanjutkan.

3. Menurunnya kesenjangan pendidikan antar kelompok masyarakat, terutama antara penduduk kaya dan penduduk kurang mampu, antara penduduk laki-laki dan perempuan, antara wilayah perkotaan dan wilayah perdesaan dan antar daerah.

4. Meningkatkan kesiapan siswa pendidikan menengah memasuki pasar kerja atau 
melanjutkan ke jenjang pendidikan tinggi.

Kartu Indonesia pintar ini diberikan keseluruh provinsi di Indonesia, sesuai dari penyedia jasa pengiriman Kartu Indonesia Pintar. Setiap daerah, masyarakat di data dan di seleksi guna mendapatkan masyarakat yang benar benar membutuhkannya. Kebijakan ini diharapkan dapat membantu perekonomian masyarakat guna membiayai pendidikan anaknya dan menekan angkan putus sekolah yang dari tahun ketahun semakin meningkat.

Berdasarkan latar belakang diatas, dapat dikatakan bahwa program pemerintah belum bisa membantu masyarakat semaksimal mungkin. Melihat belum meratanya kartu Indonesia Pintar, dibeberapa daerah Kartu Indonesia Pintar ini terkendala, contohnya di Medan, dikutip dari koran Sinar Indonesia Baru (SIB), pendistribusian Kartu Indonesia Pintar dinilai tidak tepat sasaran. Para penerima KIP sudah tidak bersekolah dan sudah menikah, menurut masyarakat pendataannya asal - asalan, banyak masyarakat yang sangat membutuhkan bantuan KIP itu, namun namanya tidak terdaftar dalam penerima KIP tersebut. Pemerintah diharapkan dapat sebijak mungkin dalam mendata siswa yang benar-benar membutuhkan, dan tepat sasaran, sebaiknya sebelum pendataan berlangsung diadakan sosialisasi agar masyarakat paham akan bantuan KIP tersebut.

\section{B. Pembahasan}

\section{Pendistribusian Kartu} Indonesia Pintar

Dalam penerapan Program Indonesia Pintar memiliki payung Hukum yang dapat dipertanggung jawabkan pelaksanaannya mulai dari pasal 34 ayat 1 dan 3 UUD 1945, UU Nomor 25/2004 tentang sistem

perencanaan pembangunan nasional yang menyebutkan bahwa janji - janji presiden saat kampanye pemilihan presiden wajib dilaksanakan sesuai dengan ketentuan peraturan perundang - undangan yang berlaku yang mengatur kewajiban negara memberikan sistem jaminan sosial bagi seluruh 
rakyat serta Instruksi Presiden

Nomor 7 Tahun 2014 tentang pelaksanaan Program Simpanan Keluarga Sejahtera, Program Indonesia Pintar, dan Program Indonesia Sehat. Program Indonesia Pintar melalui Kartu Indonesia Pintar adalah salah satu program nasional ( tercantum dalam rencana pembangunan jangka menengah nasional 2015 2019).

Dirjen Pendidikan Dasar dan Menengah Kementrian Pendidikan dan Kebudayaan (kemendikbud) mengatakan banyak siswa di beberapa daerah di Tanah Air belum menerima Kartu Indonesia Pintar (KIP) karena masalah administrasi. Dari 17,9 juta penerima KIP yang ditargetkan pada 2016 telah mampu diditribusikan sebanyak 17,4 juta kartu. Namun, permasalhannya adalah dari jumlah 17,4 juta tersebut, sekitar 10 hingga 20 persen siswa belum menerima KIP. Permasalahannya penyedia layanan pengiriman KIP tidak dikirimkan ke alamat penerima KIP diseluruh Indonesia, semua kartu hanya dikirim ke kantor camat dan kelurahan sehingga menambah pekerjaan pemerintah setempat untuk menyalurkannya.

Berdasarkan kejadian tersebut, keterangan aparat desa penyedia pengiriman hanya mengirimkan KIP ke kantor kecamatan dan desa, tidak langsung ke alamat penerima KIP, bermaslah di setiap daerah, ribuan KIP menumpuk di kantor kelurahan dan banyak penerima KIP tidak tepat sasaran dari 17 juta KIP yang dicetak pada 2015 , hanya sebesar $40 \%$ yang terserap. Untuk menghindari kejadian tersebut pemerintah mengganti mekanisme pendistribusian KIP tersebut, jadi pendistribusian KIP tersebut akan disalurkan ke sekolah sesuai data pokok pendidikan.

\section{Kebijakan publik}

Menurut Suharto dalam A Gustino (2014) hakikat kebijakan publik sebagai jenis tindakan yang mengarahkan pada tujuan yang terdiri dari bebrapa kategori sebagai berikut :

a. Tuntutan kebijakan ( Policy demand) adalah tuntutan atau desakan yang ditujukan pada pejabat - pejabat pemerintah 
yang dilakukan oleh aktor aktor lain baik swasta ataupun kalangan dalam pemerintah sendiri, dalam sistem politik untuk melakukan tindakan tertentu atau sebaliknya tidak berbuat sesuatu terhadap tindakan tersebut.

b. Keputusan Kebijakan (policy decions ) adalah keputusan yang dibuat oleh para pejabat pemerintah untuk memberikan keabsahan (Legitimasi), wewenang atau memberikan arah terhadap pelaksanaan kebijakan publik.

c. Pernyataan Kebijakan ( policy statements ) adalah pernyataan resmu atau penjelasan mengenai kebijakan publik tertentu.

d. Keluaran Kebijakan ( policy outputs ) adalah wujud kebijakan publik yang paling kongkret artinya dapat dirasakan oleh masyarakat karena menyangkut hal - hal yang dilakukan guna merealisasikan apa yang telah digarasikan dalam keputusan dan pernyataan kebijakan. e. Hasil akhir kebijakan ( policy outcomes ) adalah akibat atau dampak langsung yang benar dirasakan oleh masyarakat baik yang diharapkan ataupun yang tidak diharapkan sebagai konsekuensinya dari adanya tidakan atau tidak adanya tindakan pemerintah dalam bidang atau masalah tertentu yang ada di masyarakat.

Kesimpulannya kebijakan politik tidak hanya mengatur segala aspek dalam tatanan negara dan tidak hanya mengatur pejabat publik tetapi mengatur juga tatanan masyarakat. Implementasi kebijakan merupakan suatu proses, serangkaian keputusan dan tindakan yang bertujuan untuk melaksanakan keputusan pemerintah atau keputusan legislasi negara yang telah dibuat atau dirumuskan sebelumnya. Proses implementasi kebijakan tidak hanya menyangkut perilaku badan - badan administratif yang bertanggung jawab untuk melaksanakan program dan menimbulkan ketaatan pada diri kelompok sasaran. Namun juga menyangkut kepada jaringan - 
jaringan politik, ekonomi dan sosial yang secara langsung atau tidak langsung dapat mempengaruhi perilaku dari semua pihak yang terlibat dengan beragam aturan spesifik, situasi yang serba ideal dari segi perundangannya yang sudah jelas, unit - unit organisasi berikut staf yang diberi tugas dan sudah terlatih dengan baik, biaya yang diperlukan sudah tersedia tentunya diperlukan penyesuaian penyesuaian.

\section{Program Indonesia Pintar}

Program Indonesia Pintar (PIP) melalui Kartu Indonesia Pintar (KIP) adalah pemberian bantuan tunai pendidikan kepada nak usia sekolah dari umur 6 tahun sampai dengan 21 tahun yang berasal dari keluarga miskin, rentan miskin yaitu pemilik Kartu Keluarga Sejahtera dan Program Keluarga Harapan (PKH) yatim piatu, penyandang disabilitas, korban bencana alam dan musibah. PIP merupakan bagian dari penyempurnaan Program Bantuan Siswa Miskin (BSM). Sasaran utama dari program PIP ini adalah peserta penerima Kartu Indonesia Pintar, peserta didik dari keluarga miskin atau rentan miskin dengan pertimbangan khusus seperti yatim piatu, penyandang disabilitas, korban bencana alam dan musibah dan peserta didik SMK yang menempuh studi keahlian kelompok bidang Pertanian, Perikanan, Kehutanan, Pelayaran dan Kemaritiman.

Untuk penggunaan KIP, penerima harus terdaftar sebagai peserta didik di lembaga pendidikan formal seperti SD, SMP, SMA/SMK atau pendidikan non formal seperti Pusat Kegiatan Belajar Masyarakat (PKBM) Surat Keterangan Bebas (SKB) dan Lembaga Khusus Pelatihan (LKP) dan peserta KIP harus terdaftar di data pokok pendidikan (Dapodik) lembaga pendidikan.

Program KIP ini ditujukan untuk menghilangkan hambatan ekonomi siswa untuk bersekolah, tidak dapat dipungkiri bahwa penduduk di Indonesia masih banyak yang berpenghasilan dibawah rata - rata, pekerjaan tidak tetap, dan kurangnya lapangan pekerjaan hal tersebut sangat mempengaruhi pendapatan penduduk, sehingga anak - 
anaklah yang menjadi korban

untuk berhenti sekolah, karna kondisi ekonomi keluarga. Dengan banyaknya anak yang berhenti sekolah akan menjadikan angka putus sekolah semakin meningkat dari tahun ketahun, faktor yang mempengaruhinya adalah biaya pendidikan yang tinggi, maka Program Indonesia Pintar ini, melalui Kartu Indonesia Pintar membantu anak agar tidak mempunyai pikiran untuk berhenti sekolah karna masalah biaya. Selain untuk menghindari anak putus sekolah, program ini juga ditujukan untuk merekrut atau menarik kembali siswa yang pernah putus sekolah agar dapat mengenyam pendidikan seperti sebelumnya.

Banyaknya anak dibawah umur yang putus sekolah dan bekerja di bawah umur, program ini tidak hanya membantu untuk memenuhi biaya pendidikan anak, namun juga membantu anak dalam memenuhi kebutuhan pemebelajarannya, seperti seragam, sepatu, tas, alat tulis dan lainnya. Program Indonesia Pintar ini juga mendukung program pemerintah Wajib Belajar 12

Tahun. Karna KIP berlaku hingga siswa berumur 21 Tahun, maka siswa dapat lebih terbantu dengan adanya KIP tersebut. KIP juga mencangkup anak usia sekolah yang tidak berada di sekolah seperti Penyandang Masalah Kesejahteraan Sosial (PMKS) seperti anak di Panti Asuhan/Sosial, anak jalanan, dan pekerja anak dan difabel.

Jadi untuk siswa yang berada di panti asuhan bisa mendapatkan KIP, anak jalanan yang putus sekolah akan terjamin pendidikannya, dan untuk difabel yang mempunyai kebutuhan khusus dapat terbantu. Dengan adanya KIP dan siswa penyandang difabel dapat tersalurkan ke dalam keahlian dan kebutuhan sesuai keistimewaan yang dimiliki. KIP juga berlaku di Pondok Pesantren, Pusat Kegiatan Belajar Masyarakat dan Lembaga Kursus dan Pelatihan yang ditentukan oleh pemerintah.

KIP menarik siswa yang tidak terdaftar di satuan lembaga pendidikan untuk kembali bersekolah dan KIP menjamin 
keberlanjutan bantuan anatar jenjang pendidikan sampai tingkat SMA/ SMK dan sederajat. Jadi program pemerintah Wajib Belajar 12 Tahun akan berjalan dengan baik, dengan adanya bantuan dari Kartu Indonesia Pintar. Maka siswa diseluruh Indonesia akan terjamin pendidikannya sampai jenjang yang tinggi.

Untuk KIP disetiap daerah harus pintar untuk menyeleksi siswa yang benar - benar membutuhkan agar tepat sasaran. Untuk pendataan penerimaan KIP ini, siswa diseleksi menurut data sekolah, hal ini dapat memungkinkan kurang efektif karna siswa data di sekolah bisa saja sudah lama, seperti di Medan dengan menggunakan data dari sekolah, pemerintah mengambil data yang sudah lama, sehingga siswa yang mendapat KIP adalah siswa yang sudah lulus dan sudah menikah, siswa yang benar benar membutuhkan namanya tidak tercantum. Seharusnya untuk pendataan pemerintah dapat mengambil data yang terbaru, agar siswa yang benar - benar membutuhkan dapat terbantu dengan baik. Jika tidak sekolah dapat mengirim rekapitulasi siswa yang kurang mampu di setiap sekolahnya agar tepat sasaran.

Alangkah baiknya jika pendataan penemrima KIP dapat dilakukan oleh perangkat desa, dimana perangkat desa lebih mengerti masyarakat yang membutuhkan. Perangkat desa bekerja sama dengan sekolah untuk survei keadaan dan kondisis siswa penerima KIP, agar tidak salah sasaran. KIP ini merupakan penyempurnaan dari BSM ( Bantuan Siswa Miskin), KIP ini merupakan program yang intinya dapat membantu siswa untuk tidak putus sekolah dan menarik kembali siswa yang sudah putus sekolah karna biaya, jadi melalui KIP ini tidak ada alasan lagi tentang putus sekolah yang dilatar belakangi oleh biaya karna untuk biaya administrasi sekolah sudah ditanggung BOS ( Biaya Operasional Sekolah) dan untuk biaya perlengkapan sekolah sudah dibantu KIP.

Untuk besaran dana KIP setiap jenjang pendidikan berbeda, SD/MI/Diniyah formal 
ula/SDTK, pondok pesantren dan kejar paket A /PPS wajar pendidikan dasar sebesar Rp. 400.000,. untuk SMP/MTs/Diniyah formal wustha/SMPTK, podok pesantren, kejar paket B/PPS wajar dikdas wustha sebesar Rp. 500.000,. dan untuk SMA/SMK/MA/diniyah formal ulya/muadalah/SMTK/SMAK.

Pondok pesantren, dan kejar paket C/PMU ulya/ Lembaga Pelatihan/ kursus sebesar Rp. 700.000,.

\section{Tujuan Program Indonesia} Pintar

a. Meningkatkan peluang bagi anak usia 6 tahun sampai 21 tahun untuk mendapatkan peluang menempuh pendidikan dari Sekolah Dasar (SD) sampai dengan Sekolah Menengah Atas (SMA) atau Sekolah Menengah Kejuruan (SMK) Sederajat dan untuk mendukung program wajib belajar 12 tahun yang telah ditetapkan oleh pemerintah.

b. Mencegah terjadinya siswa putus sekolah dan tidak melanjutkan ke jenjang lebih tinggi dikarenakan masalah biaya dan ekonomi. c. Menarik kembali siswa yang putus sekolah karena masalah biaya dan siswa yang tidak melanjutkan sekolah agar mendapatkan pendidikan dengan semestinya.

d. Mendapatkan layanan pendidikan di sekolah atau Sanggar Kegiatan Belajar (SKB) atau Pusat Kegiatan Belajar Masyarakat (PKBM) atau Lembaga Khusus Pelatihan (LKP) atau Satuan Pendidikan NonFormal lainnya dan Balai Latihan Kerja (BLK).

Dari tujuan diatas pemerintah sangat menjamin generasi bangsa untuk mendapatkan pendidikan sampai ke tingkat SMA, tidak hanya pendidikan yang diterima oleh para siswa namun balai pelatihan dan sanggar juga mendukung proses dari pendidikan, jadi siswa mendapatkan pengetahuan juga keterampilan. Pemerintah juga telah menyediakan bagi siswa yang istimewa dengan pendidikan inklusi di sekolah luar biasa, dan siswa yang mengenyam pendidikan dipondok pesantren mendapatkan bantuan sesuai 
kebutuhannya. Jadi, Program Indonesia Pintar ini sangat menyeluruh tidak hanya fokus pada sekolah Formal, namun pada pendidikan Non Formal juga mendapat bantuan. Pemerintah berharap dari PIP ini dapat membantu siswa dan bermanfaat untuk siswa yang membutuhkan.

\section{Prinsip Pelaksanaan Program} Indonesia Pintar

a. Efisien yaitu menggunakan dana dan daya yang ada untuk mencapai sasaran yang ditetapkan dengan waktu yang telah ditetapkan dan dapat dipertanggung jawabkan.

b. Efektif yaitu harus sesuai dengan kebutuhan dan dapat memberi manfaat kepada yang membutuhkan.

c. Transparan yaitu menjamin keterbukan dalam masyarakat yang dapat mengetahui dan mendapatkan informasi mengenai PIP.

d. Akuntabel yaitu pelaksanaan dapat dipertanggung jawabkan.

e. Kepatutan yaitu penjabaran kegiatan harus dilaksanakan secara realistis dan proporsional. f. Manfaat yaitu pelaksanaan program atau kegiatan harus sesuai dengan prioritas utama nasional.

Jadi, prinsip dalam PIP saling berhubungan satu dengan yang lainnya, jika satu unsur tidak berjalan dengan baik maka akan mempengaruhi unsur yang lain dengan begitu PIP tidak akan berjalan sesuai dengan harapan pemerintah. Maka diharapkan dari berbagai kalangan untuk mendukung penuh pelaksanaan PIP ini, agar masyarakat yang sangat membutuhkan dapat terbantu dengan adanya program ini.

\section{Sasaran Program Indonesia Pintar}

Berdasarkan Permendikbud No. 12 Tahun 2015, sasaran PIP adalah anak berusia 6 tahun sampai 21 tahun dengan kriteria sebagai berikut :

a. Siswa atau anak dari keluarga pemegang Kartu Perlindungan Sosial (KPS) / Kartu Keluarga Sejahtera (KKS).

b. Siswa atau anak dari keuarga Program Keluarga Harapan (PKH). 
c. Siswa atau anak yang berstatus yatim/piatu atau yatim piatu dari pantai sosial / pantai asuhan.

d. Siswa yang tidak bersekolah (drop out) yang diharapkan kembali bersekolah.

e. Siswa yang putus sekolah akibat biaya.

f. Siswa yang terkena dampak ekonomi akibat bencana alam

g. Siswa dari keluarga miskin atau renta miskin yang terancam putus sekolah.

\section{Prosedur untuk mendapatkan} kartu indonesia pintar

Kartu Indonesia Pintar merupakan program penyempurna Bantuan Siswa Miskin (BSM), melalui KIP ini siswa dari keluarga kurang mampu dapat menerima bantuan tunai dari pemerintah secara reguler. Untuk tahap awal Kartu Indonesia Pintar diberikan bersamaan dengan pemberian Kartu Keluarga Sejahtera (KKS) dan Kartu Indonesia Sehat (KIS).

Penerima Kartu Indonesia Pintar (KIP) adalah anak usia sekolah dari pemegang Kartu Perlindungan Sosial (KPS) atau Kartu Keluarga Sejahtera (KKS). Siswa jenjang SD/MI, SMP/MTs,
SMA/SMK/MA adalah siswa yang mendapat Kartu Indonesia Pintar (KIP). Untuk penerima KIP belum merata kesemua pemegang KKS karena penerima KIP dilakukan secara bertahap. Untuk menerima KIP, pemegang KKS harus membawa kartunya dan dilengkapi dengan Kartu Keluarga atau surat keterangan dari RT/RW/Lurah/Kepala Desa yang menyatakan bahwa siswa tersebut dari keluarga penerima KKS dan selanjutnya dibawa ke sekolah atau madrasah tempat anak tersebut terdaftar. Selanjutnya, pihak sekolah memproses berkas tersebut untuk dicatat kedalam daftar calon penerima Kartu Indonesia Pintar, lalu menyerahkan ke Dinas Pendidikan/Kantor Kementrian Agama Kabupaten/Kota yang selanjutnya mengirimkan rekapitulasi calon penerima KIP ke Kementrian Pendidikan dan Kebudayaan/ Kementrian Agama. Untuk sekolah dibawah naungan Kemendikbud, operator sekolah wajib memasukkan informasi siswa dalam sistem Data Pokok Pendidikan (Dapodik). Setelah 
menerima rekapitulasi dari calon penerima Kartu Ondonesia Pintar (KIP), Kemendikbud/Kemenag akan mencetak dan mengirimkan Kartu Indonesia Pintar ke alamat sekolah. untuk keluarga pemegang Kartu Perlindungan Sosial (KPS) yang telah menjadi penerima BSM, masih dapat menggunakan Kartu tersebut untuk didaftarkan menjadi penerima KIP, caranya dengan KPS dibawa ke sekolah atau madrasah untuk didaftarkan sebagai penerima KIP.

\section{Cara Menggunakan Kartu Indonesia Pintar}

Pertama, calon penerima Program Indonesia Pintar (PIP) membawa dan menunjukkan Kartu Indonesia Pintar (KIP) dengan membawa Kartu Keluarga ke sekolah/madrasah/ satuan pendidikan formal maupun non formal, dimana siswa tersebut terdaftar.

Kedua, lembaga pendidikan akan mencatat informasi anak untuk didaftarkan sebagai calon penerima KIP, yang akan diajukan ke kemendikbud atau kemenag

$$
\text { Ketiga, Kementrian }
$$

Pendidikan dan Kebudayaan (kemendikbud) atau Kementrian Agama (Kemenag) akan menerbitkan Surat Keputusan (SK) penerima KIP ke lembaga atau bank penyalur yang ditunjuk.

Keempat,

Dinas

pendidikan/Kantor,

Kemenag

Kabupaten atau kota akan mengirimkan surat pemberitahuan penerima KIP ke sekolah/madrasah/lembaga

pendidikan lainnya.

Kelima, sekolah/madrasah/lembaga pendidikan lainnya akan menginformasikan kepada orang tua/peserta didik mengenai lokasi dan waktu pengambilan dana berdasarkan informasi dari Dinas Pendidikan.

Keenam, peserta didik bersama orang tua dapat mengambil bantuan dana KIP ke lembaga/bank penyalur dengan membawa KIP dan salah satu bukti pendukung seperti surat keputusan atau identitas lainnya (KTP atau Kartu Pelajar).

\section{Pemanfaatan Program} Indonesia Pintar

Pemanfaatan menurut kamus besar Bahasa Indonesia (Dedikbud 
: 2003), menyebutkan bahwa pemanfaatan berasal dari kata dasar guna, faedah. Kemudian mendapat imbuan pe-an yang mengandung arti yaitu proses, cara dan perbuatan memanfaatkan sesuatu dalam hal ini pemanfaatan terhadap efektivitas penggunaan alokasi dana Bantuan Siswa Miskin (BSM) atau Program Indonesia Pintar (PIP) terhadap kegiatan pembiayaan dalam proses pembelajaran selama menempuh pembelajaran.

Pemanfaatan dana Program Indonesia Pintar (PIP) berdasarkan petunjuk teknis antara lain : 1 . Pembelian alat tulis sekolah; 2. Pembelian pakaian dan perlengkapan sekolah (sepatu, tas, dII); 3. Transportasi siswa ke sekolah; 4. Uang saku siswa kesekolah; 5. Biaya kursus/les yang tidak diselenggarakan pihak sekolah; (Kemendikbud : 2015)

Dana Program Indonesia Pintar diterima langsung oleh pihak siswa atau orang tua, penerima wajib menggunakan dana dengan sebijak mungkin dan sesuai dengan ketentuan. Orang tua sebagai pemegang dana PIP diharapkan dapat mengelola semaksimal mungkin agar dapat berguna dengan baik dan bermanfaat untuk pemenuhan kebutuhan sekolah anak. Dengan demikian anak akan terjamin pendidikannya sampai ke jenjang yang lebih tinggi sesuai dengan program pemerintah wajib belajar 12 tahun.

\section{Kesimpulan}

Dari uraian diatas dapat disimpulkan bahwa Program Indonesia Pintar (PIP) melalui Kartu Indonesia Pintar (KIP) dapat membantu meringankan biaya pendidikan bagi siswa yang kurang mampu. Program ini juga dimaksudkan untuk menekan angka putus sekolah dan mengembalikan siswa yang sudah tidak bersekolah kembali bersekolah seperti sebelummnya. PIP ini adalah penyempurnaan dari BSM (Bantuan Siswa Miskin), siswa tidak lagi mempunyai alasan untuk tidak sekolah karna masalah biaya karna biaya administrasi sudah di tanggung oleh BOS ( Bantuan Operasional Siswa) dan untuk perlengkapan seperti alat 
tulis, seragam, sepatu dan tas dibantu dengan KIP tersebut.

KIP ini merupakan suatu bentuk dorongan untuk mempermudah program WAJAR 12 tahun (Program Belajar 12 Tahun) yang nantinya dapat membantu siswa dalam menempuh pendidikan sampai tingkat SMASMK sederajat. Bantuan tersebut tidak hanya dikhususkan untuk siswa namun juga untuk penyandang disabilitas, pondok pesantren dan Lembaga Pelatihan Kusus. Jadi, semua yang seharusnya sangat membutuhkan dapat dibantu dengan adanya KIP ini.

\section{DAFTAR PUSTAKA}

Agus Setyani, S. (2016). Laporan kegiatan ppl lokasi dinas pendidikan Kota yogyakarta judul: implementasi program indonesia pintar di sma $\mathrm{n} 9$ dan 10 yogyakarta tahun 2016. Laporan PPL.

Astuti, R. S. (2016). Implementasi kebijakan kartu indonesia pintar dalam upaya pemerataan pendidikan tahun pelajaran 2015/2016 di smp $n$
1 semin (Doctoral dissertation, KP).

Astuti, R. S. (2017). Implementasi kebijakan kartu indonesia pintar dalam upaya pemerataan pendidikan tahun ajaran 2015/2016 di smp n 1 semin. Spektrum Analisis Kebijakan Pendidikan, 6(2), 121-127.

Awalin, Septia. 2017. Efektivitas Pemanfaatan Program Indonesia Pintar Siswa Di Desa Ngrayun Untuk Pemenuhan Wajib Belajar 9 Tahun. Vol 5 (3)

Baswedan, A. R. (2014, December). Gawat darurat pendidikan di Indonesia. In The Emergency of Indonesian Education]. A paper delivered at the meeting between Ministry and Head of Education Offices Indonesia-wide in Jakarta, on December (Vol. 1).

Budi, W. (2016). Evaluasi Pemanfaatan Program Indonesia Pintar Di Smk Cokroaminoto Pandak (Doctoral dissertation, UNY). 
Didaktik : Jurnal Pendidikan Guru Sekolah Dasar, ISSN : 24775673

Sekolah Tinggi Keguruan dan IImu Pendidikan Subang Volume IV Nomor 1, Juli 2018

Dadang. 2015. Pengertian, Tujuan,

Prinsip, Pelaksanaan, dan

Sasaran PIP Berdasarkan

Permendikbud No. 12 Tahun

2015 tentang Program

Indonesia Pintar.

http://www.dadangjsn.com/20

15/07/pengertian-tujuan-

prinsip-pelaksanaan.html

diunduh tanggal 19 Februari

2018 pukul 16.46 WIB.

Kendi, Sumar. 2016. Analisis

Masalah Pendistribusian

Kartu Indonesia Pintar (KIP)

dalam Pelaksanaan

Kebijakan Publik Program

Indonesia Pintar (PIP) Di

Indonesia.

documen.tips_analisis-

masalah-pendistribusian-

kartu-kip-dalam-pdf diunduh

tanggal 7 Februari 2018

Pukul 18.27 WIB.

Kepala, V. A., \& Kepala, V. A.

(2016). LAPORAN PPL

PELAKSANAAN PROGRAM

INDONESIA PINTAR

MELALUI KARTU

INDONESIA PINTAR (KIP) DI

SMK YOGYAKARTA.

Laporan PPL.
Lusiana,

L.

(2017).

IMPLEMENTASI PROGRAM INDONESIA PINTAR (PIP) DI

DESA

SUKOMULYO

KECAMATAN

SEPAKU

KABUPATEN PENAJAM

PASER UTARA

Nasution, C. R., SpPD, K. G. E. H., \& Kes, M. (2016). Kebijakan dalam Implementasi SPGDT di Indonesia. Materi dipresentasikan pada Acara Seminar Nasional dan Workshop.

Safira, I. (2017). EFEKTIFITAS PROGRAM INDONESIA PINTAR TERHADAP UPAYA PENINGKATAN

KESEJAHTERAN

MASYARAKAT DALAM PERSPEKTIF EKONOMI ISLAM (Studi Di Kelurahan Kupang Teba Kecamatan Teluk Betung Utara Kota Bandar Lampung) (Doctoral dissertation, UIN Raden Intan Lampung).

SAFITRI, D. P., AP, S., EDISON, S., \& PA, M. IMPLEMENTASI PROGRAM KARTU INDONESIA PINTAR DI 
KOTA TANJUNGPINANG SARTIKA.

Santari, A. N., \& Sunarya, D. M. (2017). STRATEGI HUMAS KEMENTERIAN

PENDIDIKAN

DAN

KEBUDAYAAN

DALAM

MENYOSIALISASIKAN

PROGRAM INDONESIA

PINTAR MELALUI KARTU

INDONESIA

PINTAR.

PANTAREI, 1(01).

Saputra, M. R., \& Muhibbin, A.

(2017). Implementasi Hak

Pendidikan Pada Siswa

Miskin (Studi Kasus Realisasi

Program Kartu Indonesia

Pintar di SMA Negeri 1

Gondang Kabupaten Sragen)

(Doctoral dissertation,

Universitas Muhammadiyah

Surakarta).

Saputra, M. R., \& Muhibbin, A.

(2017). Implementasi Hak

Pendidikan Pada Siswa

Miskin (Studi Kasus Realisasi

Program Kartu Indonesia

Pintar di SMA Negeri 1

Gondang Kabupaten Sragen)

(Doctoral dissertation,

Universitas Muhammadiyah

Surakarta).
Saraswati, Lilis Novia. 2017. Implementasi Kebijakan Program Indonesia Pintar (PIP) Pada Jenjang Sekolah Dasar DI Kecamatan Sungai Pinang Kota Samarinda. Vol $5(4)$.

Sitorus, R. A., \& Sos, S. (2016). Tantangan dan Harapan Pendidikan Kejuruan di Indonesia dalam mewujudkan Sekolah Menengah Kejuruan yang memiliki daya saing Ketenagakerjaan.

Kemendikbud (7 Januari 2017). HIm, 4.

Sulhan, M . 2017. Implementasi Kebijakan Program Penanggulangan Kemiskinan Melalui Kartu Penjamin Sosial Dan Kartu Indonesia Pintar Pada Masyarakat (Studi Kasus di Kelurahan Kauman Kota Malang) Vol 6 (1)

Sulhan, M., \& Sasongko, T. (2017). Implementasi Kebijakan Program Penanggulangan Kemiskinan melalui Kertu Penjamin Sosial dan Kartu Indonesia Pintar pada Masyarakat (Studi Kasus di Kelurahan Kauman Kota 
Malang). Fakultas IImu Sosial dan IImu Politik, 6(1).

Suripto, N. F., Astuti, P., \& Astrika,

L. (2015). Evaluasi Kebijakan Kartu Jakarta Pintar Tingkat Sma/smk Negeri Di Jakarta Selatan (Periode Tahun Ajaran 2013-2014). Journal of Politic and Government Studies, 4(2).

Wulansari, D. J., Murtiyasa, B., \& Kom, M. (2017). Sistem Pendukung Keputusan Untuk Menentukan Penerima Kartu Indonesia Pintar Menggunakan Metode Simple Additive Weighting (Doctoral dissertation, Universitas Muhammadiyah Surakarta).

Wulansari, M. S., Timan, A., \& Nurabadi, A. EVALUASI PROGRAM INDONESIA PINTAR TINGKAT SEKOLAH MENENGAH PERTAMA NEGERI SE KABUPATEN MOJOKERTO THE EVALUATION OF PROGRAM INDONESIA
PINTAR IN PUBLIC JUNIOR HIGH SCHOOL DISTRICT OF MOJOKERTO.

Rujukan lainnya :

http://hariansib.co/view/Medan-

Sekitarnya/154716/Pendataan-

dan-Pendistribusian-Kartu-

Indonesia-Pintar-Dinilai-Tidak-

Tepat-Sasaran-di-Kota-

Medan.html Diunduh tanggal 8 Februari 2018 Jam 09.42 WIB Instruksi presiden Nomor 7 tahun 2014 tentang Pelaksanaan Program Simpanan Keluarga Sejahtera, Program Indonesia Pintar, Dan Program Indonesia Sehat Untuk Membangun Keluarga Produktif.

Kementrian Pendidikan dan Kebudayaan. 2016. Tanya Jawab Kartu Indonesia Pintar.

http://indonesiapintar.kemdi kbud.go.id/ diunduh tanggal 8 Februari 2018 pukul 10.14 WIB. 